ORIENTAL JOURNAL OF CHEMISTRY

An International Open Free Access, Peer Reviewed Research Journal

www.orientjchem.org
ISSN: 0970-020 X

CODEN: OJCHEG

2015, Vol. 31, No. (1):

Pg. 317-326

\title{
Phytoextraction of Heavy Metals by Two Sorghum Spices in Treated Soil Using Black Tea Residue for Cleaning-uo the Contaminated Soil
}

\author{
PARISA ZIARATI*, NINA NARIN ZIARATI², \\ SEPIDEH NAZERI ${ }^{3}$ and MOJTABA SABER-GERMI ${ }^{4}$
}
${ }^{1}$ Department of Medicinal Chemistry, Pharmaceutical Sciences Branch, Islamic Azad University (IAUPS), Tehran, Iran.
${ }^{2}$ Katedralskolan School, Linköping, Sweden.
${ }^{3}$ Faculty of Pharmacy, Pharmaceutical Sciences Branch, Islamic Azad University (IAUPS), Tehran, Iran.
${ }^{4}$ Faculty of Pharmacy, Tehran University of Medical Sciences, Tehran, Iran.
*Corresponding author E-mail: ziarati.p@iaups.ac.ir

http://dx.doi.org/10.13005/ojc/310136

(Received: December 28, 2014; Accepted: January 24, 2015)

\begin{abstract}
In order to investigate the effect of adding black tea leaves residue to contaminated soil due to enhance accumulating potential of heavy metals by sorghum spice an experiment was carried out. The contaminated soil by heavy metals mixed by remaining infusion of black tea ( $8: 1)$. Sorghum Bicolor and halepence were cultivated into the research soil study. Results showed that S. Halepence transition factors for all heavy metals in treated soil were higher than one and as expected the heavy metal uptake rate by S. Bicolor plant is significantly affected by tea leaves added to soil of plant cultivated .
\end{abstract}

Key words: Sorghum halepence, Phytoremediation, Heavy Metals, Contaminated soil, Black tea residue.

\section{INTRODUCTION}

The industrial pollution in some provinces and areas such as Mazandaran province in lowland rice areas in Dashte-Naz, Mazandaran and Goharbaran is a major environmental issue as there is a great pole of agricultural and rice production in
Iran. Heavy metal contamination is an increasing problem associated with agricultural areas because the soil is treated with contaminated wastes in these areas. Furthermore the phosphate fertilizers which contain cadmium (Cd) are overused in these areas instinctively. Consequently, chemical contamination especially heavy metal should be 
driven as soon as possible in these areas. Although heavy metals such as Nickel, Chrome, Lead, cadmium and etc. are not necessary for plant growth, however they are passionately taken up and accumulated by plants up to toxic levels ${ }^{1-4}$. In public attitude, phytoremediation technology is more favorable due to its potential for cleaning up environment and the overall aesthetic perfection of the contaminated sites ${ }^{5-7}$. Plants are ideal agents for soil and water remediation because of their unique genetic, biochemical and physiological features ${ }^{8-12}$.

Sorghum (Sorghum bicolor) is the most important crop in the semi-arid tropical areas because it produces large amounts of crops under extreme drought or heat conditions ${ }^{13-15}$. The sorghums have been cultivated from the past to the present, especially in different parts of Africa and India, are derived from the original sorghums

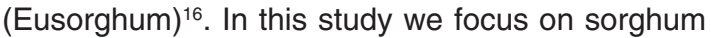
for phytoremediation purpose as the main features can be attributed to the sorghum including: fourcarbon photosynthetic pathway, tolerance to the heat, the capability to produce large amount of crops at drought conditions and high biomass. Sorghum halepence has been identified as one of 10 important weeds in the world. Studies showed that this plant in cultivating of sugar can, corn, soya, and cotton caused to the reduction of crops, and the rate of this reduction depend on the rate of density and interference and environment conditions from 24 to 87 percent $^{17}$. S. halepence is from geramine species withalmost 450 genus and 6000 species have been identified. S. halefense is a monocotyledon plant and from wheat family. The weeds of sorghum are annually, tall, thick stem and sometimes with tall and width leaves. The s. halefense species grows in different regions of Iran such as Minodasht (around Gorgan) Khorram Abad, Mazandran, PanjAb Darreh Hezar (Lahijan), Kerman, Ghazvin, Tehran and it's around ${ }^{18-19}$. As tea leaves are very rich in nitrogen and contain a lot of different micro nutrients that will help enrich the soil. They are best used for houseplants as you can easily add a small amount at a time. Compost tea organic farming is a popular traditional way to boost plant productivity on the other hand a positive correlation was found between $\mathrm{Pb}$ and $\mathrm{Cd}$ levels in root of some plants and in the tea added soil in some research studies. In 2014 , Ziarati et al.,22 found out that Lavendula Angustifoli L. plant in infusion green and black tea leaves in soils samples had more potential $(25.3 \%)$ to uptake and concentrate heavy metals than conventional soil. In 2013 Ahmadi et al., in the other study on Geranium (pelargonium roseum ) concluded that in the soil which consisted of dried black and green tea leaves had suitable ability for phytoremediation by phytoextraction method and transmitting more Lead and Cadmium in $\mathrm{pH} 6.3-6.5$ after $35-45$ days of growth and adding tea leaves has the significant effect on the enhancing cleaning-up the soil from heavy metals ${ }^{10}$.

As different regions of Iran are suitable for cultivation of sorghum and further the presence of vast area worthy for cultivation and the probable consequent of companion of black tea residue can boost the potential ability of phytoremediation sorghum conducting this research in order to:

1) Determine the potential ability of Sorghum bicolor L. and Sorghum halepence in companion of black tea residue for cleaning up Contaminated Soil and their probable capability of these plants to phytoextract more heavy metals (Nickel, Copper, Cobalt, Chrome, Lead and Cadmium).

2) Compare of the phytoextraction rates for both plants based on different growth stages of the plant.

3) Determine metal transfer factors from soil (TFS) of Sorghum spices and its companion of tea residue in the contaminated soil individually and in companion of each other due to find the possible role of black tea leaves residue in boosting phytoremediation potential.

\section{MATERIAL AND METHOD}

\section{Study Area}

In winter, spring and summer 2014 , composite soil samples were collected from depth of $0-40 \mathrm{~cm}$ from soil samples of 25 cites from 10 rice paddy farmlands and crop farmlands in the Dashte-Naz and Goharbaran in Mazandaran province $\left(36^{\circ} 38293 \mathrm{~N}, 53^{\circ} 112373 \mathrm{E}\right)$ in Iran . The soil for the survey mixed thoroughly, then transferred to greenhouse in Tehran County and mixed by remaining infusion black tea $(8: 1)$. This 
research was conducted of industrial pollution in Mazandaran province in lowland rice areas in the area of Dashte-Naz, Mazandaran and Goharbaran due to the soil surveys of kalantari et al., in 2006 and Amini et al., in 2005 which they revealed that soils from there were very high concentrations of Cadmium, lead and boron in three villages in Dashte-Naz and Goharbaran areas ${ }^{19,20}$. These areas have been polluted by sewage sludge produced by chemical industries. The sewage by high heavy metal contents is disposed directly into agricultural lands and are being used to irrigate lowland rice. According to the heavy metal contents in the soil of this area, a shallow composite soil samples (depth of $0-40 \mathrm{~cm}$ ) were collected of heavy metal contaminated soil of polluted aria and this soil sample put in a greenhouse in the county of Tehran and plants grown and not grown in it by different $\mathrm{pHs}$ after every 10 days in 60 day studying.

In the beginning of study soil profile characteristics were observed and recorded by a pocket penetrometer ( $C L-700 \mathrm{~A}$, soil test Inc. USA). Soil samples were mixed, homogenized and separated into halves. Half of each sample was air -dried and passed through a $2 \mathrm{~mm}$ sieve and used to determine $\mathrm{pH}(1: 1)$ and electrical conductivity (EC 1:1). The other half was passed through a 2 $\mathrm{mm}$ sieve without drying and used to determine nitrate and ammonium (2M KCl extraction followed by determination using flow injection method, potentially mineralizable nitrogen (PMN) and moisture content. PMN was measured in duplicate for surface layers. All the soil data are expressed on a dry weight basis.

\section{Heavy Metal Analysis}

Sorghum Bicolor and halepence (one month old plants) were grown in a local nursery until transplant into the research study. For metal analysis $5 \mathrm{~g}$ of shoots along with leaves and roots of 60 numbers of two Sorghum Bicolor and halepence plants sample were taken separately in every ten day in this study during 60 days. $8 \mathrm{ml}$ of concentrated nitric acid (65\%) and $1 \mathrm{ml}$ of perchloric acid $(70 \%)$ was added and $1 \mathrm{ml}$ hydrogen peroxide $(9-12,21)$. Application of concentrated $\mathrm{HNO}_{3}$ along with thirty percent hydrogen peroxide $\mathrm{H}_{2} \mathrm{O}_{2}$ (Merck) for mineralization of samples to the complete digestion of samples ${ }^{7,22}$ following Environmental
Protection Agency (EPA) Method 3052 was done.

All glassware and plastic containers used were washed with liquid soap, rinsed with water, soaked in $10 \%$ volume/volume nitric acid at least overnight, and rinsed abundantly in deionized water and dried in such a manner to ensure that any contamination does not occur. Five-point calibration curves (five standards and one blank) were constructed for each analyte. The calibration curve correlation coefficient was examined to ensure an $r^{2} \leq 0.998$ before the start of the sample analysis. The digested samples were diluted with $10 \%$ HNO3 and brought up to $50 \mathrm{~mL}$ and analyzed by a graphite furnace atomic absorption spectrophotometry, (GFAAS). The measurements were performed using a PerkinElmer PinAAcle 900T atomic absorption (AA) spectrophotometer and using at least five standard solutions for each metal. All recoveries of the metals studied were greater than 95\%Digestion followed by the measurement of total concentrations of Cd using Atomic Absorption Spectrophotometer using an air-acetylene flame for heavy metals : $\mathrm{Pb}$, $\mathrm{Cd}, \mathrm{Co}, \mathrm{Cu}, \mathrm{Cr}, \mathrm{Ni}, \mathrm{Zn}$ and $\mathrm{Cu}$. All necessary precautions were taken to avoid any possible contamination of the sample as per the AOAC guidelines Physical and chemical properties and concentrations of heavy metals ( Chrome, Zinc, lead, Cadmium, Copper, Cobalt and Nickel ) in soils before and after planting sorghum and also after the growth period( in every 10 days ) measured ${ }^{23-27}$. In order to assess amount of heavy metals transfer from soil to plant (shoot and root), translocation factor was determined by dividing metal concentration at shoot by its concentration at $\operatorname{root}^{28}$. Different parts of Plant samples (shoots, roots and leaves) were separated and washed and digested by wet method according the standard protocol for measuring Cadmium and Lead. The uptake rate is given by the following equation ${ }^{12,22}$.

$$
\mathrm{U}=(\mathrm{TSCF})(\mathrm{T})(\mathrm{C})
$$

\section{Where}

$\mathrm{U}=$ uptake rate of contaminant, $\mathrm{mg} /$ day

TSCF = transpiration stream concentration factor, dimensionless

$\mathrm{T}=$ transpiration rate of vegetation, L/day

$\mathrm{C}=$ aqueous phase concentration in soil water or groundwater, $\mathrm{mg} / \mathrm{L}$. 
The ratios were higher than one it was considered as suitability of plant at that condition for use in phytoremediation. The enrichment factor (EF) has been calculated to derive the degree of soil contamination and heavy metal accumulation in soil and in plants growing on contaminated site with respect to soil and plants growing on uncontaminated soil $(12,22)$. Metal contents were detected by Atomic Absorption Spectrophotometer by wet digestion method in Research Laboratory in Pharmaceutical Sciences Branch University.

The last port used to determine nitrate and ammonium $2 \mathrm{M} \mathrm{KCl}$ extraction followed by determination using flow injection method. All the soil data are expressed on a dry basis.

\section{Statistical Method}

Mean values were calculated, and analysis of variance (ANOVA) and Student's t-test were performed. Bioaccumulation factors (BAF-s) were calculated for heavy metal contents of plant parts $(\mathrm{mg} / \mathrm{kg}) /$ heavy metal content of soil $(\mathrm{mg} / \mathrm{kg})$, for each metal.

\section{RESULTS AND DISCUSSION}

Chemical extraction of the soil profile before planting sorghum and adding black tea residue samples is shown in the table 1 . As plant availability of certain heavy metals depends on soil properties such as soil $\mathrm{pH}$ and contains exchange capacity and on the distribution of metals among several soil fractions $(9,10)$. , electrical conductivity (ds/cm), pH and $\mathrm{NO}_{3}$ and $\mathrm{NH}_{4} \mathrm{~N}(\mathrm{mg} / \mathrm{kg} \mathrm{DW}$ ) of soil before of study in depend on depth of layer is shown in table 2 . Data is averages of the profiles.

Results showed that S. Halepence transition factors for all heavy metals in treated soil were higher than one and S. Halepence can uptake lead, Cadmium and Nickel after 40 days $(p<0.01)$ more than other studied metals. In figure 1 the phytoremediation trend by this plant indicates that S. Halepence cultivated in the soil which is enriched by balck tea leaves can be consider as a suitable hyper-accumulator by its relatively large ratio of biomass concentration of the contaminant to soil concentration.

The rate of uptaking Cobalt by S. Bicolor leaves in treated soil was obviously high especially after 10 days ( figure 2 ). The amount of Co deposited in leaves in both Co-treated plants differed significantly $(p<0.02)$. As expected the Co uptake rate by this plant is significantly affected by time duration after plant cultivated and grown as for Nickel uptake $(p<0.01)$ while for chrome the $p$-value was less than 0.03 .

In figures 3,4,5,6 and 7 the mean contents of heavy metals in S. Bicolor leaves are reported.

Table 1: Physical and Chemical properties of soil samples before cultivated Sorghum Bicolor and halepence

\begin{tabular}{lccc}
\hline Characteristic & Quantity & Characteristic & Quantity \\
\hline Soil Texture & Silty Clay Loam & Sand $(\%)$ & 14.6 \\
Clay $(\%)$ & 39.4 & Silt $(\%)$ & 46 \\
$\mathrm{Ni}(\mathrm{mg} / \mathrm{kg} \mathrm{DW})$ & 2.8342 & $\mathrm{Cd}(\mathrm{mg} / \mathrm{kg} \mathrm{DW})$ & 1.5301 \\
$\mathrm{~Pb}(\mathrm{mg} / \mathrm{kg} \mathrm{DW})$ & 8.1207 & $\mathrm{Cu}(\mathrm{mg} / \mathrm{kg} \mathrm{DW})$ & 5.2201 \\
$\mathrm{Co}(\mathrm{mg} / \mathrm{kg} \mathrm{DW})$ & 0.8392 & $\mathrm{Cr}(\mathrm{mg} / \mathrm{kg} \mathrm{DW})$ & 3.7656 \\
\hline
\end{tabular}

Table 2: The characteristics of Dashte-Naz and Goharbaran soil samples comparing with their depth and $\mathrm{pH}$

Layer(depth cm) $\quad \mathrm{pH}\left(\mathrm{H}_{2} \mathrm{O}\right) \quad$ Electrical conductivitydS/cm 1:1 $\mathrm{NO}_{3}-\mathrm{Nmg} / \mathrm{kg} \mathrm{DW} \quad \mathrm{NH}_{4}-\mathrm{Nmg} / \mathrm{kg} \mathrm{DW}$

\begin{tabular}{lllll}
\hline $1(0-20)$ & 6.4 & 0.53 & 62.3 & 10.56 \\
$2(20-40)$ & 6.7 & 0.37 & 31.2 & 10.01 \\
\hline
\end{tabular}




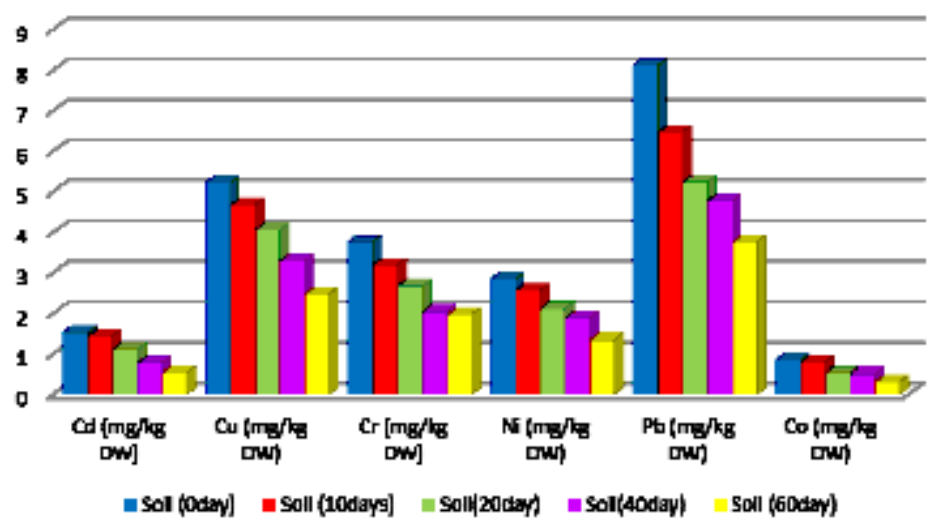

Fig. 1: Heavy metal contents ( $\mathrm{mg} / \mathrm{kg} \mathrm{DW}$ ) in soil treated by Black tea residue and S. Halepence cultivated after 60 days

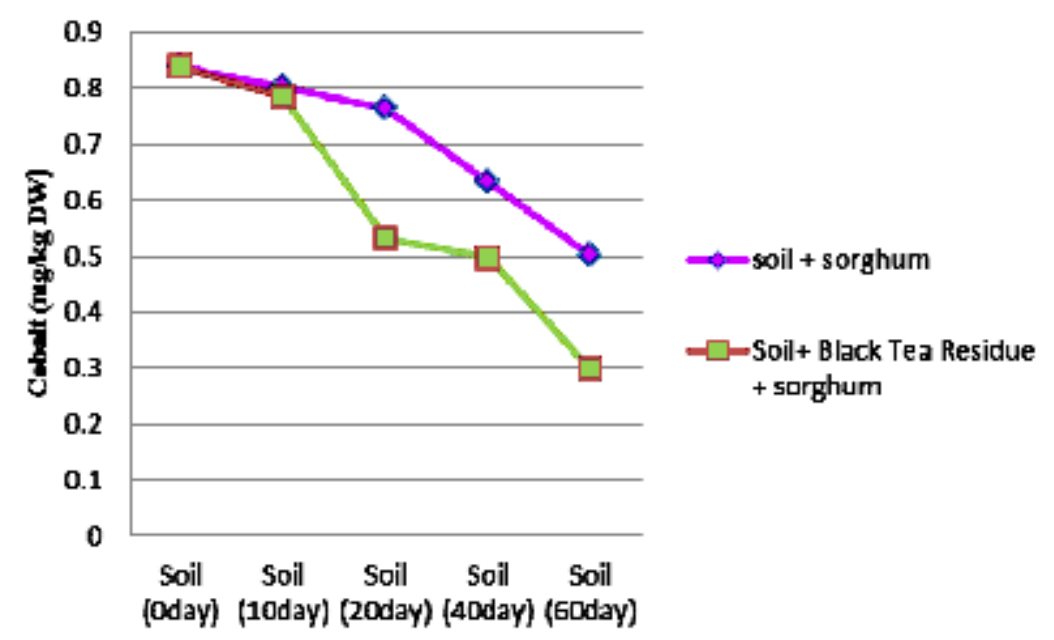

Fig. 2: Cobalt content (mg/kg DW) remaining in contaminated soil sorghum Bicolor cultivated in comparion to treated contaminated soil by Black tea residue

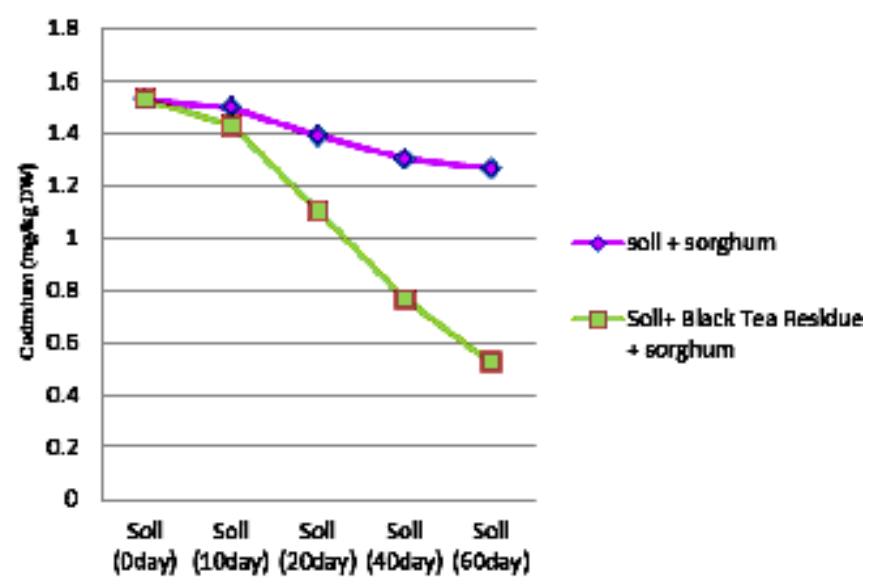

Fig. 3: Cadmium content ( $\mathrm{mg} / \mathrm{kg} \mathrm{DW}$ ) in sorghum Bicolor cultivated in contaminated soil in comparion to treated contaminated soil by Black tea residue 
The metal concentrations remained high in shoots compared to roots in $\mathrm{Cr}$ and $\mathrm{Pb}$ treated groups, while metal content was higher in shoots than roots in: $\mathrm{Co}, \mathrm{Cd}, \mathrm{Cu}$ and $\mathrm{Ni}$-treated groups. The ratios of shoot/root ratios were calculated to indicate the translocation efficiency of heavy metals from root to shoot. The $\mathrm{Cd}$ and $\mathrm{Co}$ (III) concentrations in samples after 20, 40 and 60 days are significantly higher in plant in treated than untreated soils. Even though the Nickel concentration of shoots and roots of $\mathrm{Ni}$ treated plants in 40 and 60 days treated plants is higher compared to other heavy metals. The extent of metal accumulation and uptake efficiency of $\mathrm{Pb}$ was lower than that of other metals in long term contaminated situation study. Most of plants in the untreated soil group samples died after 60 days remaining in contaminated soil while in treated group the transition factor for up-taking all of heavy metals was higher than one and all plants were alive and no obvious physical changing.

Due to soil has been subjected to maximum utilization and severely degraded or contaminated because of human activities, continuous efforts for building up effective technologies for keeping them free from pollution and sustain good quality of soils seems reasonable. However, for a large scale of remediation due to high costs and side effects more intricate practices are needed. Phytoremediation technique by different plant species for cleaning contaminated soils and waters has been investigated since last decade and considering as an emerging cheaper technology. Certain plants have been identified that have the potential to uptake heavy metals and about 45 families such as Brassicaceae , Fabaceae, Lamiaceae have been investigated as hyper accumulators plants. Thlaspi Among the bestknown hyper accumulators without showing any injury can accumulated up to $22 \%$ of soil exchangeable Cadmium from contaminated sites $^{29,30}$. Jadia and Fulekkkkar were found that corn, sunflower and sorghum are effective due to their fast growth rate and large amount of biomass ${ }^{31,32}$. Comparison of cadmium up-taking from contaminated soil of Sorghum cultivated in treated soil by Thlaspi as a well-known hyper accumulator , our data showed that presence of tea elevates the potential to transport Cadmium from the roots to the shoots more than thlaspi. Because of the large amount of tea consumption and making a large amount of tea residues, it is convenient and rational to use these tea residues in agriculture management. The data in figures ${ }^{2-7}$ indicated that combination between tea residues and accumulation of heavy metals by leaves of sorghum plants affected significantly $(p \leq 0.01)$ on the presence of tea leaves in soil. Adsorption kinetics reveals that up-taking rate of the heavy metals and its residence time. Results revealed that a rapid adsorption rate of $\mathrm{Cd}$ and Co followed by slower adsorption rate by tea residue. The driving force for adsorption was higher at the beginning, since the concentration difference between the 40 and 60 days were not significant. Hence, in compliance with the observed results, at longer time of being in the treated soil, higher initial adsorption rates prevailed.

Environmental pollution with metals is a global problem, and therefore the development of environmental friendly techniques such as phytoremediation technologies for plant-based clean-up of contaminated soils is a great achievement especially for some countries such as Iran. Phytoremediation technologies are currently available for small subset of pollution problems but finding the new approaches for boosting the potential ability of plants has a long contrivance. Edible plant grown in contaminated areas have high risk of having heavy metal concentrations higher than the permissible limit therefore finding the companion plants or new developing methods to clean up heavy metal contaminated soil is a major concern. In this study by changing the soil condition by separating infusion black tea leaves after brewing as a waste homemade material and adding and mixing them by contaminated soil, we improved the accumulation of heavy metals by shoots and roots of two sorghum spices. Tea residue is a cheap and readily available natural waste which can be used for up-taking heavy metals by some plants that have potential to adsorbing them. The translocation factor ratios were more than one for all plants in treated soil revealed that adding infusion tea leaves can significantly increase the hyper accumulation state of Two: Sorghum spices. The results of this research concluded that in the soil which consisted of dried black tea leaves had suitable ability for 


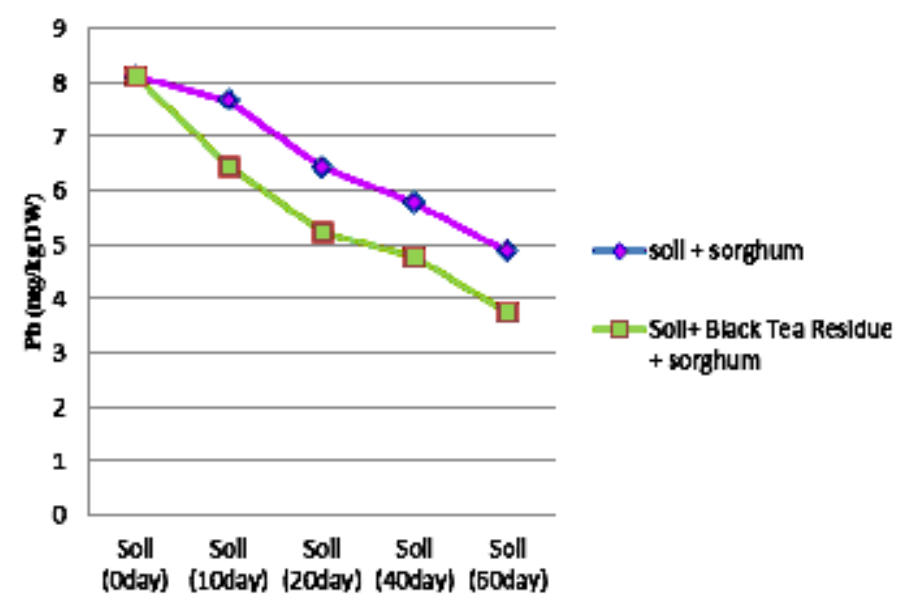

Fig. 4: Lead content (mg/kg DW) in sorghum Bicolor cultivated in contaminated soil in comparion to treated contaminated soil by Black tea residue

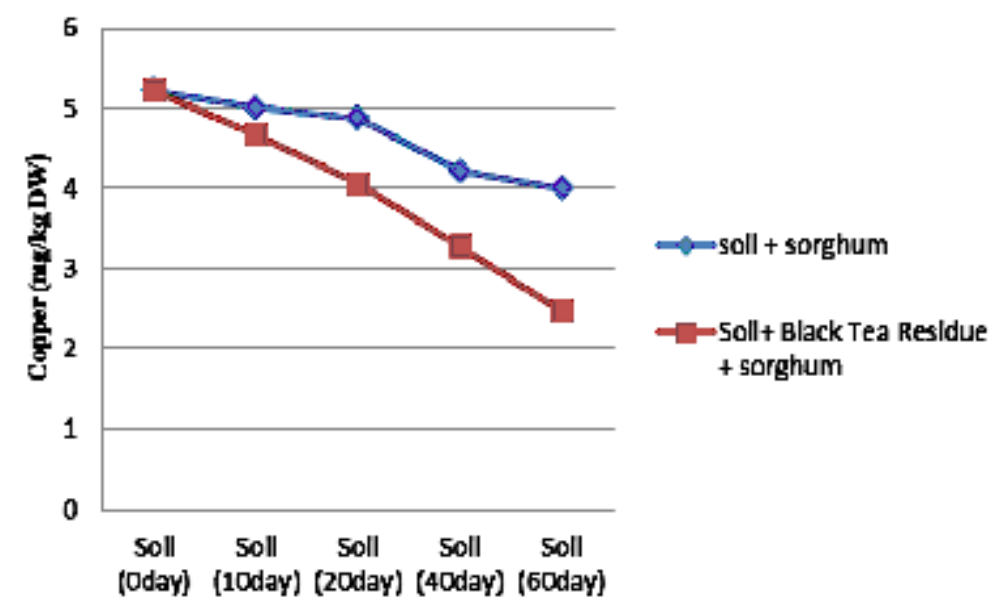

Fig. 5: Copper content (mg/kg DW) in sorghum Bicolor cultivated in contaminated soil in comparion to treated contaminated soil by Black tea residue

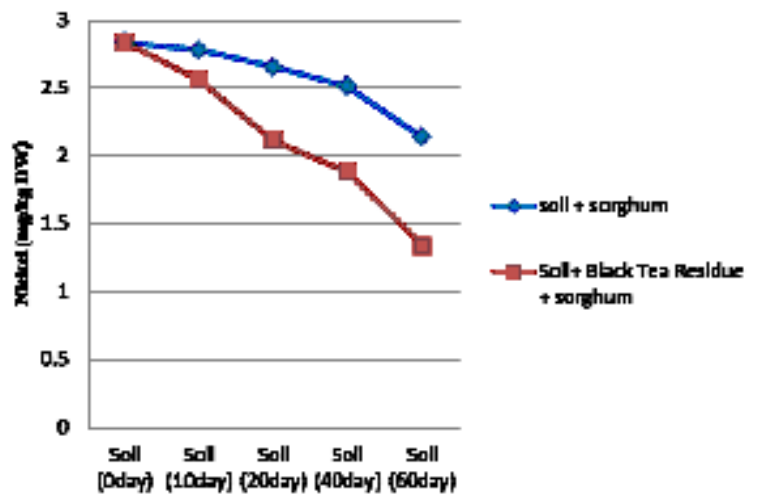

Fig. 6: Nickel content ( $\mathrm{mg} / \mathrm{kg} \mathrm{DW}$ ) in sorghum Bicolor cultivated in contaminated soil in comparion to treated contaminated soil by Black tea residue 


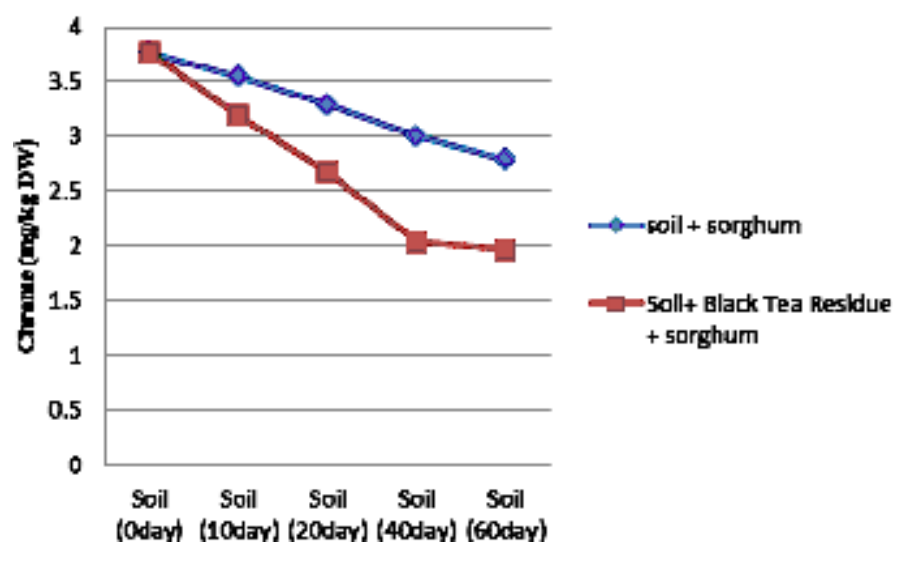

Fig. 7: Chrome content ( $\mathrm{mg} / \mathrm{kg} \mathrm{DW}$ ) in sorghum Bicolor cultivated in contaminated soil in comparion to treated contaminated soil by Black tea residue

phytoremediation by phytoextraction method and transmitting more Lead, Chrome, Nickel, Cobalt, Copper, and Cadmium in $\mathrm{pH}<7$ after 20-40 days of growth of Sorghum spices. The rate of Cadmium uptake by $\mathrm{S}$. Bicolor is significantly affected by the grown days after cultivated in contaminated treated soil as for lead uptaking $(\mathrm{p}<0.05)$ while for $\mathrm{Cd}$ uptaking $p$-value was less than 0.003 .
Regarding the results of the present study, it is recommended to study more on the species belong to other plant families that have potential ability to hyperaccumulate heavy metals especially the inedible plants.

\section{ACKNOWLEDGEMENTS}

Pharmaceutical Sciences Branch, Islamic Azad University (IAUPS) is gratefully acknowledged.

\section{REFERENCES}

1. Mussarat, M., Bhatti, A.U. Heavy metal contents in fodder crops growing in the vicinity of Peshawar city. Soil Environ. 2005, 24, 58-62.

2. Yang, T.X.; M.S. Li; Y. Li ; Huang, H.R. Study on heavy metal pollution in soil and plants in Pingle Manganese Mine, Guangxi and implications for ecological restoration. Mining Saf. Environ. Protec. 2006,1: 21-23.

3. Akguc, N.; Ozyigit I.I.; Yarci, C. Pyracantha coccinea roem. (Rosaceae) as a biomonitor for $\mathrm{Cd}, \mathrm{Pb}$ and $\mathrm{Zn}$ in mugla province (Turkey). Pak. J. Bot. 2008, 40, 1767-1776.

4. Saima, M.,; Haq Navaz, B.; Khalid, M.; Anwar ul Haq HAQ, M.; Shahzad, M.S. Potential of Sunflower (Helianthus Annuus L.) for Phytoremediation of Nickle (Ni) and Lead (Pb) Contaminated Water. Pak. J. Bot. 2010, 42(6), 4017-4026. Available in Site: http://
www.pakbs.org/pjbot/PDFs/42(6)/ PJB42(6)4017.pdf .

5. Chen, H. ; Cutright, T.J. The interactive effects of chelator, fertilizer, and rhizobacteria for enhancing phytoremediation of heavy metal contaminated soil. J. Soils Sedi. 2002, 2, 203210.

6. Fayiga, A.O.; L.Q. Ma; Cao, X.; Rathinasabapathi, B. Effects of heavy metals on growth and arsenic accumulation in the arsenic hyperaccumulator Pteris vittata L. Environ. Poll. 2004, 2, 289-296.

7. Baker, A.J.M. Accumulators and excluders strategies in the response of plants to heavy metals. Journal of Plant Nutrition. 1981, 3 , 643-654.

8. Paulo, J.C.; Favas, J. P.; Varun, M.; Rohan, D.S.; Manoj, S. P. Phytoremediation of Soils Contaminated with Metals and Metalloids at 
Mining Areas: Potential of Native Flora Chapter 17, page 492. Available in site: http:/ /cdn.intechopen.com/pdfs-wm/46355.pdf.

9. Manshadi, M.; Ziarati, P. ; Ahmadi, M.; Fekri, K. Greenhouse Study of Cadmium and Lead phytoextraction by five Pelargonium spices. International Journal of Farming and Allied Sciences. 2013, 2(18), 665-669. Available online at www.ijfas.com.

10. Ahmadi, M.; Ziarati, P.; Manshadi, M.; Asgarpanah, J. ; Mousavi, Z. The Phytoremidiation Technique for Cleaning Up Contaminated Soil by Geranium (pelargonium roseum). International Journal of Farming and Allied Sciences. 2013, 2(15), 477-481. Available online at www.ijfas.com

11. Ziarati, P.; Alaedini S. The Phytoremediation Technique for Cleaning up Contaminated Soil By sp. J Environ Anal Toxicol. 2014,4, 208. doi: 10.4172/2161-0525.1000208.

12. Ziarati, P.; Iranzad-AsI, S. ; Asgarpanah, J. companion pelargonium roseum and rosmarinus officinalis in cleaning up contaminated soil by phytoextraction technique the role of companion plants in boosting phytoremediation potential. International Journal of Plant, Animal and Environmental Sciences. 2014, 4(3) , 424430.

13. Dogget, H. Sorghum tropical. Agriculture series. 1985.London.

14. Fischer, R.A. Yield potential of dwarf spring wheat and the effects of shading. Crop Science 1975,15, 607- 613.

15. Moradi, M.; Yousefi-Rad, M.; Darbani, A. Studying capability of soil cadmium phytoremediation by sorghum in the presence of mycorrhiza fungi. International Journal of Biosciences. 2013, 3(10), 233239.

16. Alipur, H. Agriculture and Plant Breeding in Forage Crops (Sorghum). Karaj, Iran: Islamic Azad University of Karaj Publications, 175 pages.( 1990). (In Persian).

17. Nouri, H.; Ansari Talab, Z.; Tavassoli, A. Effect of weed allelopathic of sorghum (Sorghum halepense) on germination and seedling growth of wheat, Alvand cultivar. Annals of Biological Research, 2012, 3 (3),1283-1293. Available online at: www.scholarsresearchlibrary.com.

18. Jafari, L. MSc Thesis of Agronomy.Shiraz University. Iran. 1999; 112.

19. Amini, M.; Afyuni, M.; Fathianpour, N.; Khademi, H.; Fluhler, HContinuous soil pollution mapping using fuzzy logic and spatial interpolation. Geoderma, 2005, 124, 223-233.

20. Kalantari, M.R.; Shokrzadeh, M. ; Ebadi , A.G.; Mohammadizadeh, C.; Choudhary, M.I. ; Atta-ur-Rahman . Soil Pollution by Heavy Metals and Remediation (Mazandaran-Iran). Journal of Applied Sciences. 2006, 6, 21102116.

21. Ziarati, P.; Zolfaghari, M.; Azadi, B. the effect of tea residue in promoting phytoremediation of lavandula angustifoli mill. International Journal of Plant, Animal and Environmental Sciences. 2014, 4(2), 479-486.

22. Kisku, G.C.; Barman, S.C.; Bhargava, S.K. Contamination of soil and plants with potentially toxic elements irrigated with mixed industrial effluent and its impact on the environment. Water Air Soil Pollut. 2000, 120, 121-137.

23. Saeedifar, F.; Ziarati, P.; Ramezan, Y. Nitrate and Heavy Metal Contents in Eggplant (Solanum melongena) cultivated in the farmlands in the south of Tehran-Iran. Int/ J Farm \& Alli Sci., 2014, 3, 60-65.

24. Ziarati, P.; Khoshhal, Z.; Asgarpanah, J.; Qomi, M. Contaminations of Heavy Metals in Tea Leaves Finished Tea Products and Liquors in Gilan Province, Iran. Intl J Farm \& Alli Sci, 2013,2, 383-387. Available in Site: http://ijfas.com/wp-content/uploads/2013/07/ 383-387.pdf.

25. Mir Mohammad-Makki, F.; Ziarati, p. Determination of Histamine and Heavy Metal Concentrations in Tomato Pastes and Fresh Tomato (Solanum lycopersicum) in Iran . Biosciences Biotechnology Research Asia. 2014, 11(2), 537-544.

26. Webster's New Geographical Dictionary, 1980 edition. G. \& C. Merriam, Springfield, MA, 1980.

27. Praveen, S. Application note Atomic Absorption , 2011, available in site : www.perkinelmer.com.

28. Rego, T.J.; Nagesvara Rao, V.; Seeling, B.; 
Pardhasaradhi, G.; Kumar Rao, D.K. Nutrient balances a guide to improving sorghum and ground based dry land cropping systems in semi-arid tropical India. Field Crops Res. 2003, 81, 53-68.

29. Mullins, G.L.; Sommers, L.E.; Barber, S.A. Modeling the plant uptake of Cadmium and Zinc from soils treated with sewage-sludge. J. Soil Sci. Am. 1986, 50, 1245-1250.

30. Brown, S.L.; Chaney, R.L.; Angle J.S.; Baker, A.J.M. Zinc and cadmium uptake by hyperaccumulator Thlaspi caerulescens grown in nutrient solution. Soil Sci. Soc. Am. J. 1995, 59,125-133.

31. Jadia, C.D.; Fulekar, M.H. Phytotoxicity and remediation of heavy metals by fibrous root grass (sorghum). Journal of Applied Biosciences. 2008, 10, 491-499. www. biosciences.elewa.org .

32. Pilon-Smits, E. Phytoremediation, Annu. Rev. Plant. Biol. 2005, 56, 15-39. Available at: arjournals.annualreviews.org 